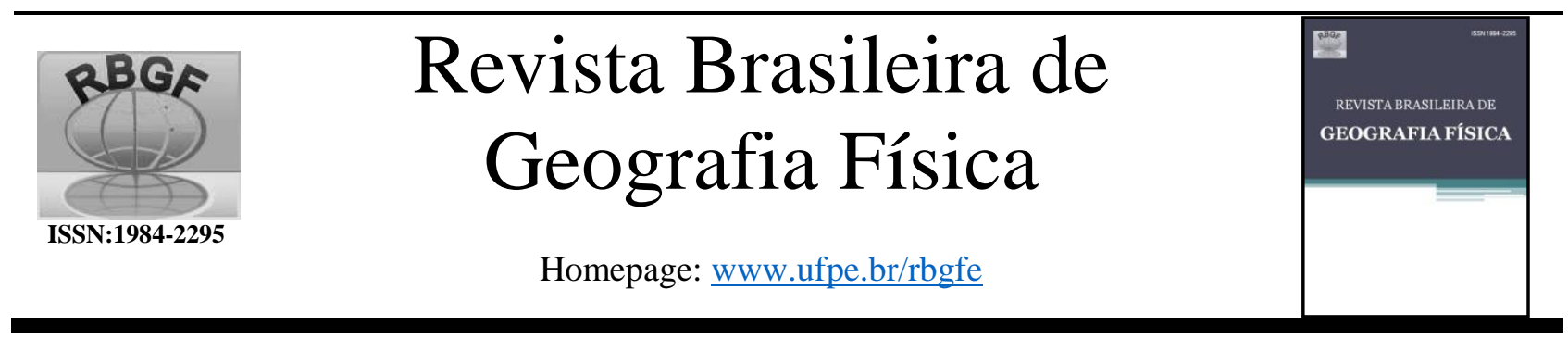

\title{
Cobertura vegetal em microbacias urbanas: análise temporal da cobertura arbórea e temperatura de rondonópolis, Mato Grosso
}

Dhonatan Diego Pessi ${ }^{1}$, Greyce Bernardes de Mello Rezende ${ }^{2}$, Normandes Matos da Silva ${ }^{3}$ Mestrando em Gestão e Tecnologia Ambiental pela Universidade Federal de Mato Grosso - Rondonópolis-MT; ${ }^{1}$ Email: dhonatan.pessi@gmail.com 2²Doutora em Recursos Naturais e Professora Adjunto II (UFMT) - Barra do Garça-MT. ${ }^{3}$ Doutor em Ecologia de Ecossistemas Terrestres e Aquáticos e Professor Associado I (UFMT) Rondonópolis-MT.

Artigo recebido em 24/08/2018 e aceito em 14/12/2018

\section{R E S U M O}

Os objetivos deste trabalho foram quantificar a cobertura vegetal presente nas microbacias urbanas de Rondonópolis-MT e relacionar com o número de habitantes para calcular o IVC; realizar um comparativo da quantidade de cobertura vegetal nos anos de 2013 e 2017 para saber se houve déficit ou ganho de vegetação relacionando com as variações da temperatura do ar. Foi realizado o levantamento da cobertura vegetal através do NDVI e posteriormente relacionado aos valores de vegetação em $\mathrm{m}^{2}$ de cada microbacia com o número de habitantes para se obter o ICV. Já a comparação dos anos estudados (2013 e 2017) foi realizado também pelo cálculo do NDVI e posteriormente extraído os valores de NDVI para cada imagem e comparado através da correlação de Pearson e teste t pareado. Os valores de temperatura entre os anos de 2013 a 2017 foram comparados com os resultados do levantamento da vegetação. Da área total estudada (7753 hectares), a cobertura vegetal representou 622 hectares, cerca de $8 \%$ do total. O ICV para a microbacia do Escondidinho foi de 2 $\mathrm{m} 2 /$ hab. A cobertura vegetal para o ano de 2013 foi de 2.500 hectares e em 2017 foi reduzida para 1.661 hectares. Ocorreu um déficit de cobertura vegetal de 839 hectares. Os resultados da cobertura vegetal de 2013 e 2017 relacionados com a temperatura, demonstraram que houve diferenças na temperatura em locais que houve perda de vegetação, com aumento de até $1.5^{\circ} \mathrm{C}$. A cobertura vegetal exerce um importante papel na dinâmica ambiental urbana, mantendo a temperatura mais baixa, servindo como refúgio para a biodiversidade e proporcionando saúde física e mental aos habitantes.

Palavras-chave: ICV, Geoprocessamento, Bacia hidrográfica, Microclima urbano.

\section{Vegetation cover in urban microbasins: temporal analysis of the arboreal cover and temperature of Rondonópolis, Mato Grosso}

\section{A B S T R A C T}

The aims of this work were the measurement of the forest cover present on the watershed of Rondonópolis-MT and relate this with the number of inhabitants to calculate the IVC; to make a comparison of the quantity of forest cover in 2013 and 2017 in order to know if there has been deficit or gain of vegetation relating them with the air temperature. It was done the survey of the forest cover by NDVI and it was later related to the data about the vegetation in $\mathrm{m}^{2}$ of each watershed with the number of inhabitants in order to get ICV. As to the comparison of the examined years (2013 and 2017), it was done, too, by the calculation of the NDVI and later it was extracted the values of the NDVI to each image and it was compared using the Pearson's correlation and the paired t-test. The values of the temeprature between 2013 and 2017 were compared with the outcome of the survey of the vegetation. Of the total area investigated (7753 hectares), the forest cover represented 622 hectares, about $8 \%$ of the total. The ICV to the watershed of Escondidinho was $2 \mathrm{~m}^{2} / \mathrm{inh}$. The forest cover to 2013 was 2.500 hectares and in 2017 it was reduced to 1.661 hectares. There was a deficit of 839 hectares in the forest cover. The results about the forest cover of 2013 and 2017 that were related with the temperature have shown that there were differences in the temperature in places with loss of vegetation, with a temperature rise of up to $1.5^{\circ} \mathrm{C}$. The forest cover plays an important role in the urban environmental dynamics, keeping a lower temperature, serving as a refuge to the biodiversity and affording physical and mental health to the inhabitants.

Keywords: ICV, Geoprocessing, Watershed, Urban microclimate.

\section{Introdução}

As cidades brasileiras nas últimas décadas estão passando por um crescimento acentuado.
Esse fato tem refletido negativamente na qualidade de vida devido a um crescimento urbano mal 
gerido. Problemas como o empobrecimento da paisagem, presença de assentamentos precários, poluição do ar, poluição sonora e a deterioração dos componentes ambientais, se devem, em parte a má gestão pública (Souza et al., 2014; Scheuer; Neves, 2016).

Os principais fatores que levaram Rondonópolis a altos índices de expansão urbana desde a década de 80 , deve-se ao mercado agrícola e a atração de emprego em busca de oportunidades (Negri, 2008; Demamann, 2011), inserindo Rondonópolis em um nível de crescimento econômico acima do esperado para cidades de médio porte no Brasil (Negri, 2008).

$\mathrm{O}$ crescimento urbano reflete na qualidade de vida e está relacionado a fatores como a infraestrutura, desenvolvimento econômico, social e ambiental que, nesse caso, se refere às áreas arborizadas. Essas áreas possuem um papel importante para o bem estar da população (Loboda; Angelis, 2005). De acordo com Oliveira Filho et al. (2013), espaços com paisagem arborizada, suscitam benefícios à qualidade de vida urbana, como o sombreamento, conforto térmico, redução da poluição do ar e elementos estéticos positivos. Há ainda outros aspectos como o bem estar físico e psíquico do ser humano, incluindo o aumento da biodiversidade e a preservação de espécies nativas (Boeni; Silveira, 2011).

Esses ambientes devem estar disponíveis à toda população e buscam atender às necessidades e anseios de lazer, e nesse contexto, a possibilidade de interação com o ambiente natural (Bargos; Matias, 2011). Pessoas que vivem em áreas construídas com acesso a jardins e parques, têm menor prevalência de desordens mentais comparado com pessoas que não possuem acesso a essas áreas (Martínez-Soto et al., 2016).

Conforme Tucci (1997), a urbanização tem como efeito o desmatamento, a degradação das áreas de mananciais e a impermeabilização nos centros urbanos, contribuindo para o aumento de inundações e alagamentos (Rezende; Araújo 2016). Áreas de mananciais e a impermeabilização nos centros urbanos, contribuem para o aumento de inundações e alagamentos (Rezende; Araújo 2016).

Entender como funciona a dinâmica das microbacias urbanas e qual o seu grau de cobertura vegetal, torna-se uma ferramenta importante na gestão municipal, levando em conta os problemas que são causados pela falta de cobertura vegetal, impermeabilização do solo, e seus efeitos negativos ao bem estar humano, relacionando, dentre outros aspectos, à carência de áreas verdes para usufruto das pessoas (Canholi, 2005).

A presente pesquisa buscou quantificar a cobertura vegetal nas microbacias urbanas de Rondonópolis-MT, por meio do Índice de Cobertura Vegetal (ICV), que foi relacionado ao número de habitantes. Além disso, houve uma análise do déficit ou ganho de cobertura vegetal e variações da temperatura do ar no período entre 2013 a 2017.

\section{Material e métodos}

\section{Área de estudo}

A área de estudo compreende a mancha urbana da cidade de Rondonópolis-MT, desconsiderando os setores industriais $\mathrm{e}$ loteamentos vagos sem área construída. Rondonópolis está localizada no sudeste do Estado de Mato Grosso, nas coordenadas geográficas

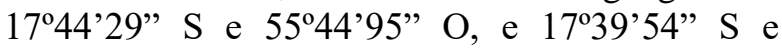
53 50 '64" O, estando a $212 \mathrm{~km}$ de distância de sua capital, Cuiabá (Figura 1).

Rondonópolis está situada no bioma Cerrado, em uma área de transição entre o Planalto dos Guimarães e a Planície do Pantanal Matogrossense (Teixeira Júnior, 2016). Possui uma macha urbana de $110 \mathrm{~km}^{2}$, e sua população estimada é de 222.316 habitantes (IBGE, 2017), com uma densidade demográfica de $47 \mathrm{hab} / \mathrm{km}^{2}$.

O clima da região de Rondonópolis é considerado megatérmico (tropical úmido), com temperatura média anual de $21^{\circ} \mathrm{C}$, sendo a média das máximas de $32,6^{\circ} \mathrm{C}$ e a média das mínimas $18,6^{\circ} \mathrm{C}$ (Sette, 2005; Souza et al., 2013). A vegetação é formada por Cerradão, Cerrado, Campos Cerrado, Formação Savânica e Floresta Estacional. As altitudes estão na faixa de 200 a 300 metros de altura. Os tipos pedológicos dessa região são principalmente o Latossolo, Neossolo, Argilossolo e o Cambiossolo (Pinheiro et al., 2008; Santos et al., 2018). 

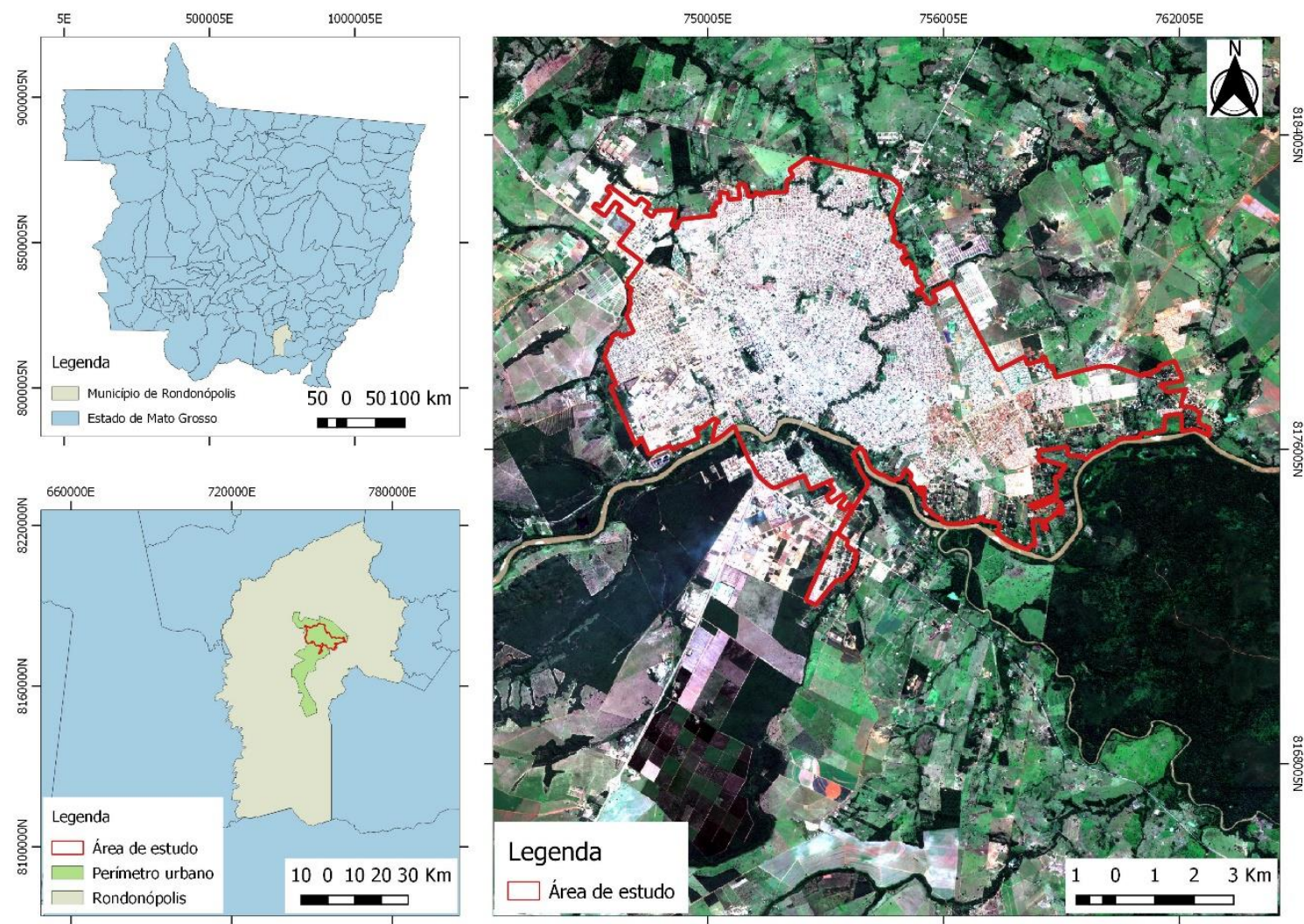

Figura 1. Mapa com a delimitação do município de Rondonópolis-MT, perímetro urbano e área de estudo. Projeção geográfica: UTM SIRGAS 2000, 21S. Dados geográficos: IBGE e Prefeitura de Rondonópolis. Imagem: Sentinel-2 (USGS). Elaboração: O próprio autor.

\section{Aquisição das imagens de satélite}

Foi utilizado uma cena do satélite Sentinel2 com resolução espacial de 10 metros datado de 14/05/2018. Na análise temporal das diferenças da área coberta por vegetação no espaço urbano em hectares de vegetação nos últimos 5 anos (2013 a 2017), foram utilizadas imagens do satélite Landsat 8, com resolução espacial de 30 metros, tendo banda pancromática com pixels que possuem 15 metros de resolução. Para transformar os pixels das demais bandas para 15 metros de resolução espacial, houve a fusão das bandas com a pancromática através da ferramenta pansharpen no software Quantum GIS 3.2.2 (QGIS Development Team, 2018). As imagens foram obtidas gratuitamente no site do Serviço Geológico dos Estados Unidos (United States Geological Survey) disponível no link: https://earthexplorer.usgs.gov/.

\section{Índice de Vegetação por Diferença Normalizada (NDVI)}

O NDVI é um índice que envolve a razão normalizada entre a diferença e a soma das bandas do infravermelho próximo (NIR) e o vermelho (R) (Rouse et al., 1973). Esse índice normaliza a razão simples para o intervalo de $-1 \mathrm{a}+1$, onde as áreas de vegetação mais intensa aproximam-se de +1 , e os valores próximos de 0 geralmente representam Pessi, D. P.; Rezende, G. B. M.; Silva, N. M. solo exposto. Os valores negativos indicam superfícies com água. Estas duas bandas espectrais foram escolhidas porque são as mais afetadas pela absorção de clorofila na vegetação de folhas verdes e pela densidade da vegetação na superfície. $\mathrm{O}$ NDVI é calculado pela equação 1 :

$$
N D V I=\frac{N I R-R E D}{N I R+R E D}
$$

Onde: NIR = Infravermelho próximo (780-2.500 $\mathrm{nm})$; e R = Vermelho (625-740 nm).

\section{Índice de Cobertura Vegetal (ICV)}

Foi utilizado o método tradicional (ICV) proposto por Nucci e Cavalheiro (1999) onde é feito o levantamento da cobertura vegetal em metros quadrados e realizado uma divisão pelo número de habitantes da área estudada.

O ICV baseia-se na proporção da somatória da cobertura vegetal $\mathrm{em}^{2}$, e divide pelo número de habitantes daquela área levantada. $\mathrm{O}$ ICV é calculado pela equação 2 :

$$
I C V=\frac{C V\left(m^{2}\right)}{N}
$$

Onde: $\mathrm{ICV}=$ cobertura vegetal em metros quadrados; $\mathrm{N}=$ número de habitantes. 


\section{Variações climatológicas}

Os dados de temperatura para a série temporal de 2013 a 2017 foram extraídos a partir do sensor MERRA-2 produto M2SDNXSLV (Modern-Era Retrospective Analysis for Research and Applications). O MERRA-2 fornece uma análise climática viável para dados de temperatura do ar com uma resolução aproximada de $0,5^{\circ} \times$ $0,625^{\circ}$ (2 metros) e 72 níveis híbridos-eta da superfície para $0,01 \mathrm{hPa}$ (Gelaro, 2017).
Os dados do satélite MERRA-2 foram baixados gratuitamente a partir do link: https://giovanni.gsfc.nasa.gov/giovanni/. As coordenadas usadas na extração dos dados formaram um quadrante na área urbana de Rondonópolis (-54.6946O, -16.4139S, -54.5409O, -16.5170 S) conforme Figura 2. Os dados utilizados de temperatura foram as médias diárias de temperatura do ar a 2 metros de distância do solo.

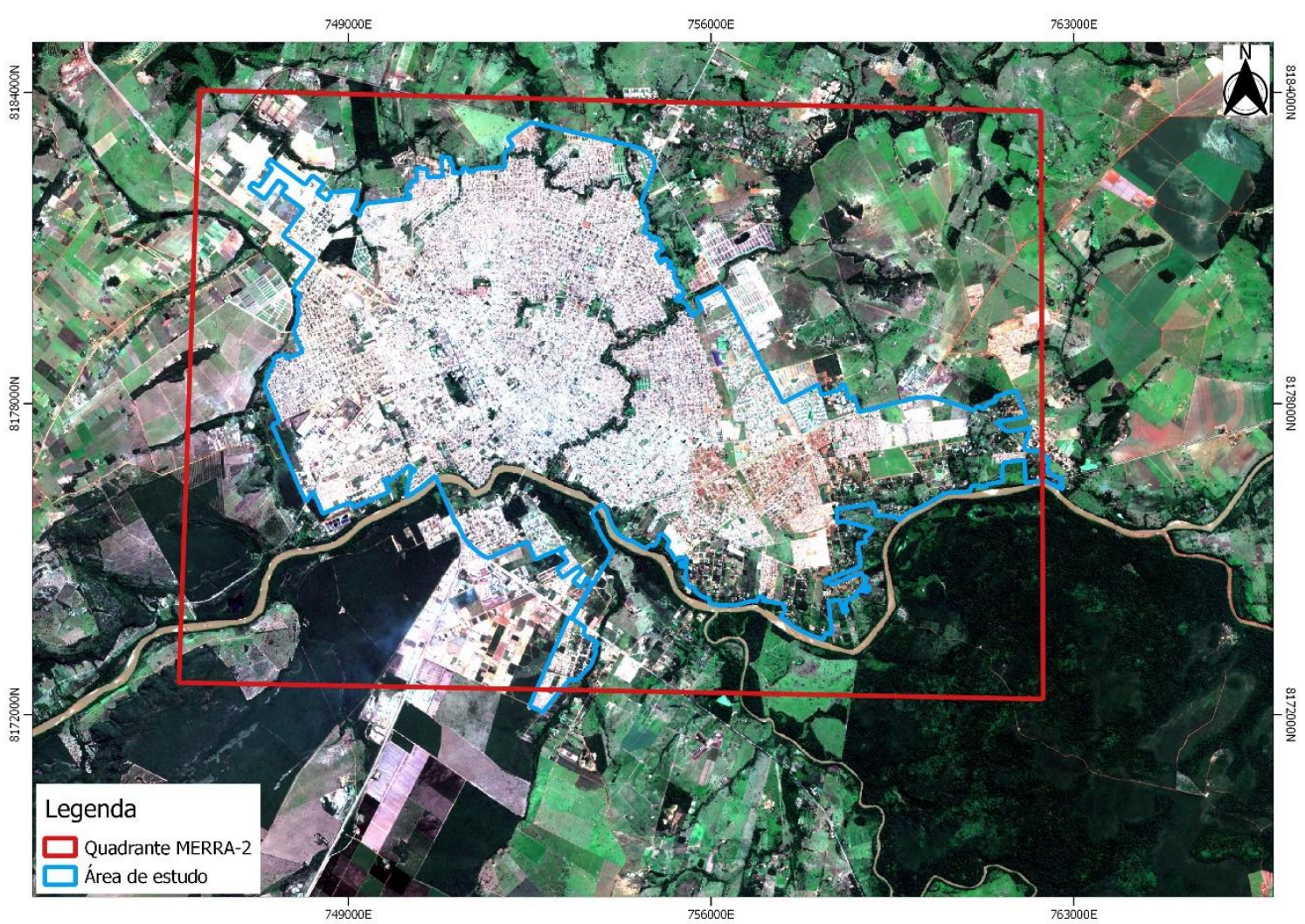

Figura 2. Mapa com o quadrante no qual foram extraídas as informações de temperatura do ar através do satélite MERRA-2.

\section{Procedimentos}

Para realizar o levantamento do número de habitantes por área, dividiu-se a área de estudo por microbacias, disponibilizadas pelo Plano Diretor Municipal da Prefeitura de Rondonópolis (2017) em formato shape, nas quais foram inseridos os bairros e o respectivo número de habitantes.

Optou-se pela unidade de trabalho (microbacia), pois são unidades de estudo usadas para entender os efeitos da impermeabilização a partir da perda de vegetação em áreas urbanas. Ao todo foram 12 microbacias presentes dentro da área de estudo (Figura 3).

Estando com a área de estudo dividida por microbacias, realizou-se o cálculo NDVI para toda $a$ área no software R 3.4.4. Os pacotes usados no $R$ para realizar os devidos cálculos das informações levantadas foram: raster (Hijmans, 2017), ggmap

(Kahle e Wickham, 2013), maptools (Bivand e Lewin-Koh, 2017), prettymapr (Dunnington, 2017), lattice (Deepayan, 2008), rasterVis (Lamigueiro e Hijmans, 2018), latticeExtra (Sarkar e Andrews, 2016).

As informações da cobertura vegetal (NDVI) para toda a área de estudo foram exportadas do sistema $\mathrm{R}$ e processadas no software Quantum GIS 3.2.2. Os dados raster de cobertura vegetal foram subdivididos em informações por $\mathrm{m}^{2}$ para cada microbacia e relacionados com a equação do ICV (Equação 2). 

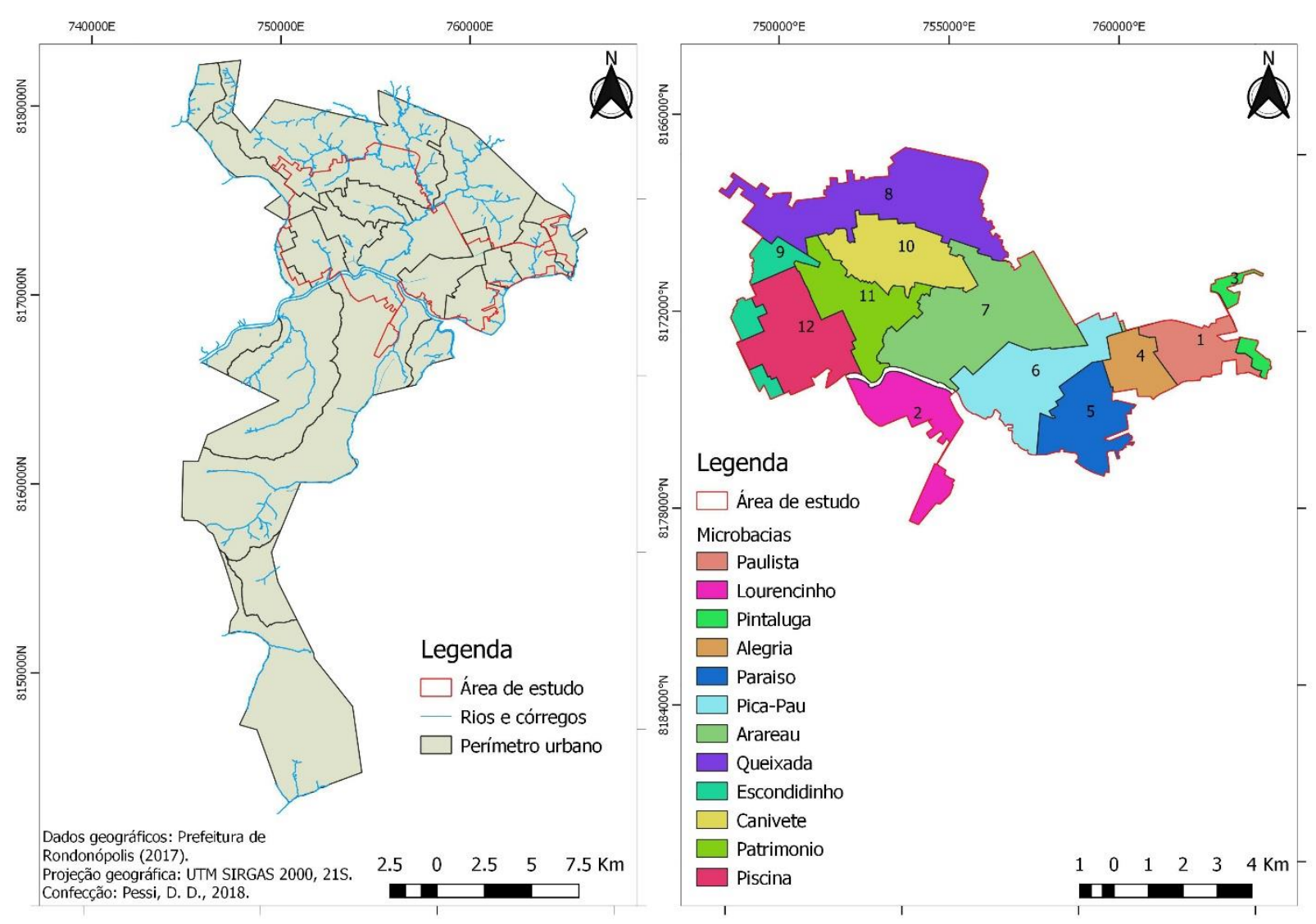

Figura 3. Localização e delimitação de cada uma das microbacias urbanas inseridas na área de estudo.

As relações temporais entre os anos de 2013 a 2017 para os dados de déficit ou ganho de vegetação e suas relações com as variações de temperatura foram realizadas no software R 3.4.4. Foram extraídos 1000 informações de pixel a partir dos dados rasters gerados para cada uma das duas variáveis estudadas, que neste caso foi o raster do ano de 2013 e o raster do ano de 2017. Foi criada uma matriz com as informações de pixel extraídas sendo que estes pixels se referem ao mesmo ponto para ambos os anos (variáveis). Após realizar este procedimento de criação de uma matriz de dados, aplicou-se os seguintes métodos estatísticos: Correlação de Pearson (r) ou coeficiente de correlação produto-momento. A correlação de Pearson mede o grau da correlação linear entre duas variáveis quantitativas. Foi aplicado também um Teste t pareado o qual analisa duas amostras pareadas de uma mesma unidade amostral, ou seja, dados pareados, onde a unidade é o seu próprio controle. O nível aplicado para o teste foi de 5\% de significância para responder se houve diferença entre as médias das amostras pareadas. Os testes estatísticos foram realizados no software $\mathrm{R}$ 3.4.4 com pacotes do próprio software (corr.test e t.test).

Os dados das variações de temperatura do ano de 2013 a 2017 foram tabulados em arquivo
CSV e imputados no software R 3.4.4 para gerar gráficos e matrizes com as informações das

variações de temperatura. Os pacotes utilizados foram: hydroTSM (Zambrano-Bigiarini, 2017), lattice (Deepayan, 2008), hydroGOF (ZambranoBigiarini, 2017).

\section{Resultados e discussão}

\subsection{Classificação NDVI e cobertura vegetal no ano de 2018}

A área de estudo possui 7.753 hectares, e desse total a cobertura vegetal representou 622 hectares, ou $8 \%$ das unidades de estudo da área (Figura 4).

Existem poucas manchas com cobertura vegetal por toda a área estudada, sendo que essas manchas são na sua grande parte áreas protegidas, como é o caso da unidade de conservação denominada de Parque Natural Municipal de Rondonópolis e a Área de Preservação Permanente (APP) do córrego Arareau.

Áreas de preservação, principalmente as APP, exercem importante papel na integridade das microbacias urbanas, em termos de proteção aos processos erosivos nas margens dos rios, provendo 
nutrientes à ictiofauna, regulação térmica e higrométrica da atmosfera, além da manutenção da

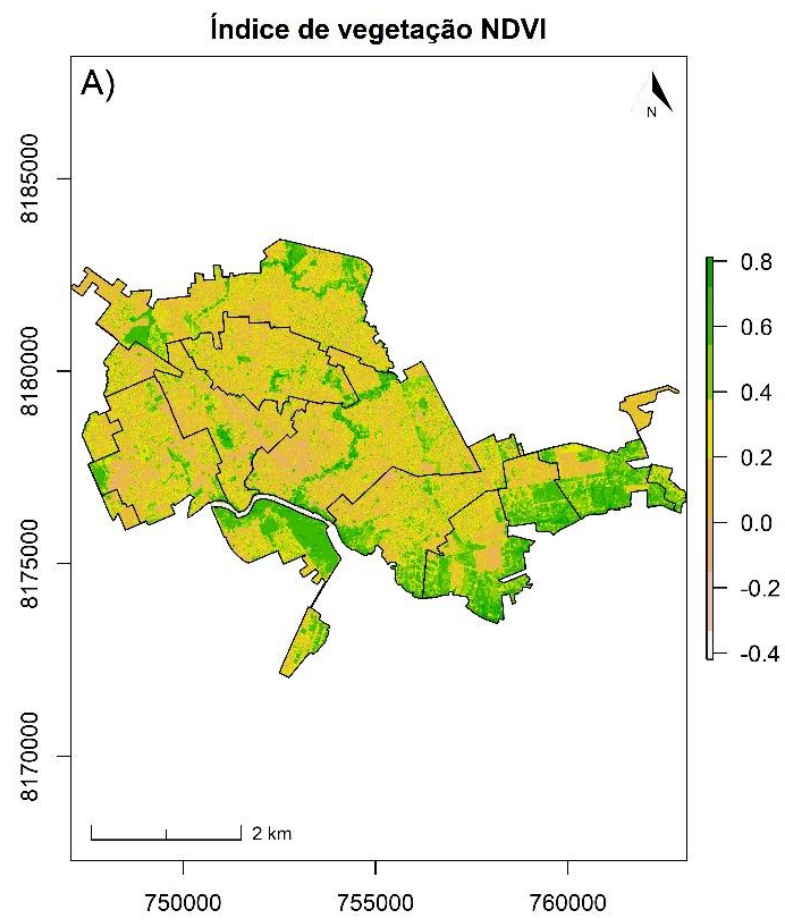

qualidade e da quantidade de água (Rezende, 2015).

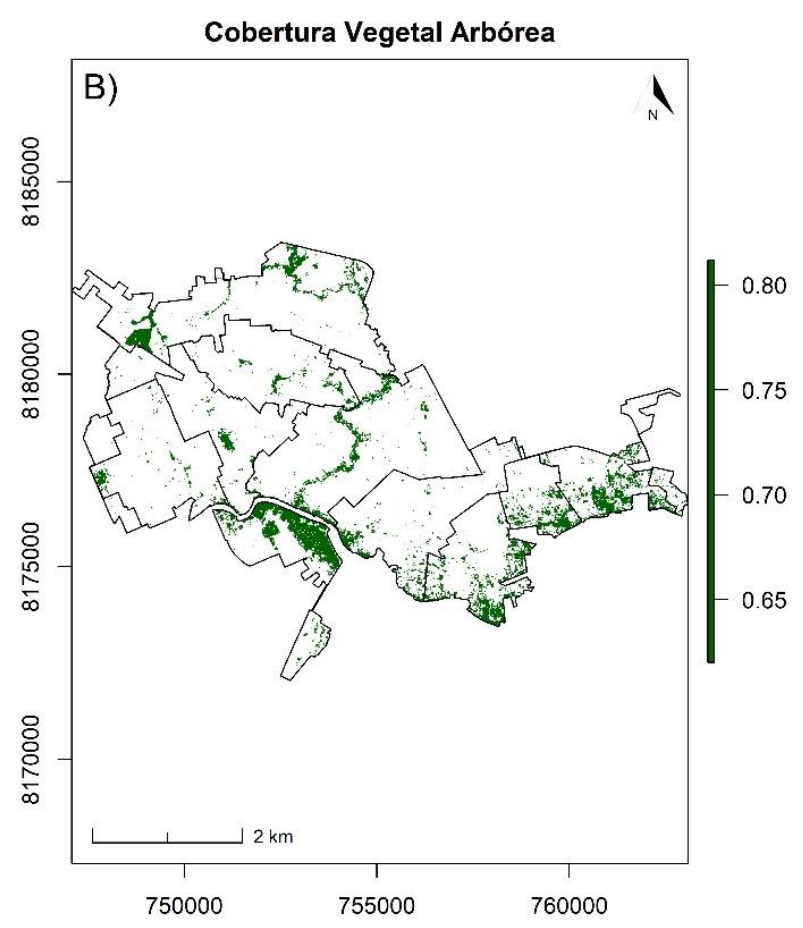

Figura 4. Classificação NDVI (A) e cobertura vegetal arbórea para toda a área construída do setor urbano (B) do município de Rondonópolis-MT para o ano de 2018.

$\mathrm{Na}$ periferia da mancha urbana de Rondonópolis, existe maior área com cobertura vegetal (Figura 4B). Tal fato também foi observado em outras pesquisas. Paula e Ferreira (2017) realizaram mapeamento da cobertura vegetal na região central da cidade de Juiz de Fora-MG, e verificaram maior presença de cobertura vegetal na região periférica da cidade, o que influencia positivamente a dinâmica da drenagem das águas pluviais (Araújo, 2016).
A microbacia do córrego Pintaluga não havia informações de população segundo o senso de 2010 do IBGE (Tabela 1). A microbacia do córrego Paulista representou ICV de $1958 \mathrm{~m}^{2}$, e isso se deve ao fato de que havia um pequeno número de moradores inseridos na microbacia e também pelo fato de ser uma região periférica e com áreas onde haviam chácaras inseridas, com alto índice de cobertura vegetal.

Tabela 1. Relação dos valores de ICV para cada microbacia, cobertura vegetal em metros quadrados e o número de população inserida por microbacia. 


\begin{tabular}{lcccc}
\hline \multicolumn{1}{c}{ Microbacias } & $\mathrm{ICV}\left(\mathrm{m}^{2} / \mathrm{hab}\right)$ & População $(\mathrm{hab})$ & Cobertura Vegetal $\left(\mathrm{m}^{2}\right)$ & Área $(\%)$ \\
\hline Córrego Alegria & 117 & 4,825 & & \\
Córrego Arareau & 22 & 39,055 & 864,856 & 7,6 \\
Córrego Canivete & 11 & 23,001 & 263,527 & 12 \\
Córrego Escondidinho & 2 & 10,580 & 22,190 & 3,5 \\
Córrego Lourencinho & 644 & 2,393 & 1.539 .094 & 0,300 \\
Córrego Paraiso & 121 & 8,844 & 1.064 .757 & 20,7 \\
Córrego Patrimônio & 13 & 16,041 & 223,878 & 14,3 \\
Córrego Paulista & 1958 & 517 & 1.012 .436 & 3 \\
Córrego Pica-Pau & 28 & 16,743 & 483,860 & 13,5 \\
Córrego Pintaluga & - & - & 47,090 & 6,5 \\
Córrego Piscina & 17 & 13,758 & 246,821 & 0,6 \\
Córrego Queixada & 25 & 42,458 & 1.062 .875 & 3,3 \\
\hline
\end{tabular}

A microbacia do córrego Pintaluga não havia informações de população segundo o senso de 2010 do IBGE (Tabela 1). A microbacia do córrego Paulista representou ICV de $1958 \mathrm{~m}^{2}$, e isso se deve ao fato de que havia um pequeno número de moradores inseridos na microbacia e também pelo fato de ser uma região periférica e com áreas onde haviam chácaras inseridas, com alto índice de cobertura vegetal.

A microbacia do córrego Lourencinho apresentou a maior área de cobertura vegetal $\left(1.539 .094 \mathrm{~m}^{2}\right)$ e ICV de $644 \mathrm{~m}^{2}$. Isso se deve a áreas anteriormente particulares e que estão sendo desapropriadas as quais possuem considerável cobertura vegetal o que consequentemente aumentou o índice. $\mathrm{O}$ menor índice foi verificado na microbacia do Escondidinho com ICV de $2 \mathrm{~m}^{2}$. Neste caso, o que fez esta microbacia obter baixo valor de ICV, foi o fato de ser uma microbacia inserida na região de alta densidade urbana da cidade, ou seja, pouca cobertura vegetal e grande número de moradores inseridos nesta microbacia.

A média geral para o valor de ICV para todas as microbacias estudadas foi de $246 \mathrm{~m}^{2}$. O alto valor da média se deve principalmente pelas microbacias as quais obtiveram valores discrepantes (corrégo Paulista e corrégo Lourencinho).

Arruda et al. (2013) em estudo realizado no município de Mossoró-RN apresentaram valores para cobertura vegetal na ordem de $9,57 \mathrm{~m}^{2} / \mathrm{hab}$. Harder et al. (2002), que realizaram o estudo no município de Vinhedo-SP, chegaram ao valor de $0,55 \mathrm{~m}^{2} / \mathrm{hab}$. Nucci (2001) chegou a valores de 0,58 $\mathrm{m}^{2} / \mathrm{hab}$ para o distrito de Cecília-SP. Comparativamente, os resultados de ICV para Rondonópolis estão acima da média dos estudos

Pessi, D. P.; Rezende, G. B. M.; Silva, N. M. aqui citados. Os valores de ICV para toda a área de estudo analisada, foram desiguais, ocorrendo as menores médias na região central da cidade e com valores altos na periferia (Tabela 1) e nas margens do rio Vermelho. Em comparação com as cidades citadas, as quais não configuram o mesmo aspecto paisagístico quando comparadas com Rondonópolis, pois esta por sua vez, possui reservas de vegetação inseridas na área de estudo, como é o caso do Horto florestal, além da APP do córrego Arareau e do rio Vermelho, que estão inseridos na área de estudo e exercem grande influência no aumento do ICV em determinadas microbacias, como por exemplo, na microbacia do córrego Lourencinho, que possui influência da APP do rio Vermelho e do Horto florestal que é uma unidade de conservação.

A cobertura vegetal confere proteção às nascentes e mananciais, valorização visual e ornamental, recreação e a quebra da monotonia paisagística das cidades (Nucci; Cavalheiro, 1999; Nucci, 2001; Angeoletto, 2008; Duarte et al., 2017), exercendo reflexo positivo na saúde mental do indivíduo, mitigando precursores psicológicos da violência como a irritabilidade, ansiedade e estresse (Duarte et al., 2017; Tian et al., 2011).

\section{Comparação da cobertura vegetal nos anos de} 2013 e 2017 e as variações da temperatura

Nos últimos cinco anos houve crescimento de áreas construídas na periferia de Rondonópolis, determinando o aumento de áreas desmatadas $\mathrm{e}$ déficit de cobertura vegetal. Em 2013 havia 2.500 hectares de cobertura vegetal na área estudada, e em 2017 esse número reduziu para 1.661 hectares. Houve um déficit de cobertura vegetal de 839 hectares (Figura 5).

Em Jatai-GO, município com características similares a Rondonópolis, houve 
déficit de cobertura vegetal entre os anos de 2004 e 2010. No ano de 2004 a cobertura vegetal representava 496 hectares, e em 2010 esse número reduziu para 232 hectares (Souza et al., 2014). Isso decorreu da falta de planejamento municipal, resultando na expansão desordenada da malha urbana, sem a preocupação com a devida distribuição de árvores necessárias e exigidas para garantir conforto térmico, paisagístico e equilíbrio ambiental (Souza et al., 2014). Essa mesma situação ocorreu em Rondonópolis, principalmente nos últimos cinco anos. Nota-se que houve uma expansão urbana sem planejamento ambiental. Tal fato pode ser verificado na periferia da cidade, onde houve um crescimento mais acentuado, não ocorrendo nenhum projeto de reserva ambiental para proteger os fragmentos florestais que haviam, ou até mesmo o planejamento de arborização das ruas, parques, e locais públicos.
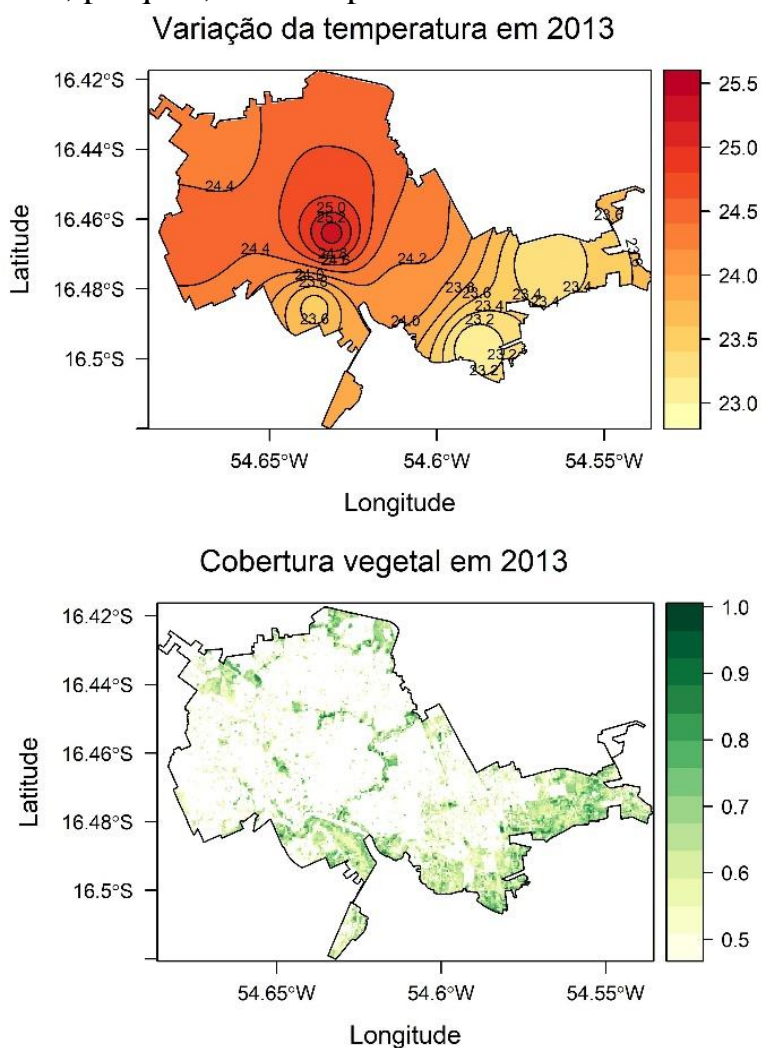

Observa-se ainda na Figura 5, que existe aumento na temperatura em algumas regiões da área estudada, principalmente na região com maior quantidade de área construída. Na região periférica da cidade também houve aumento da temperatura, sendo que no ano de 2013 havia maior quantidade de cobertura vegetal e temperaturas mais amenas $\left(23^{\circ} \mathrm{C}\right)$. Percebe-se que houve um aumento da temperatura em algumas áreas de até $1,5^{\circ} \mathrm{C}$. Conforme verificado nos resultados, existe uma relação entre densidade vegetal e temperatura. Geralmente o aumento da temperatura nas cidades, deve-se à supressão vegetal e também à áreas edificadas, tendo em vista que onde ocorre menor densidade de vegetação, os valores da temperatura tendem a aumentar, conforme demonstram os resultados da Figura 5.
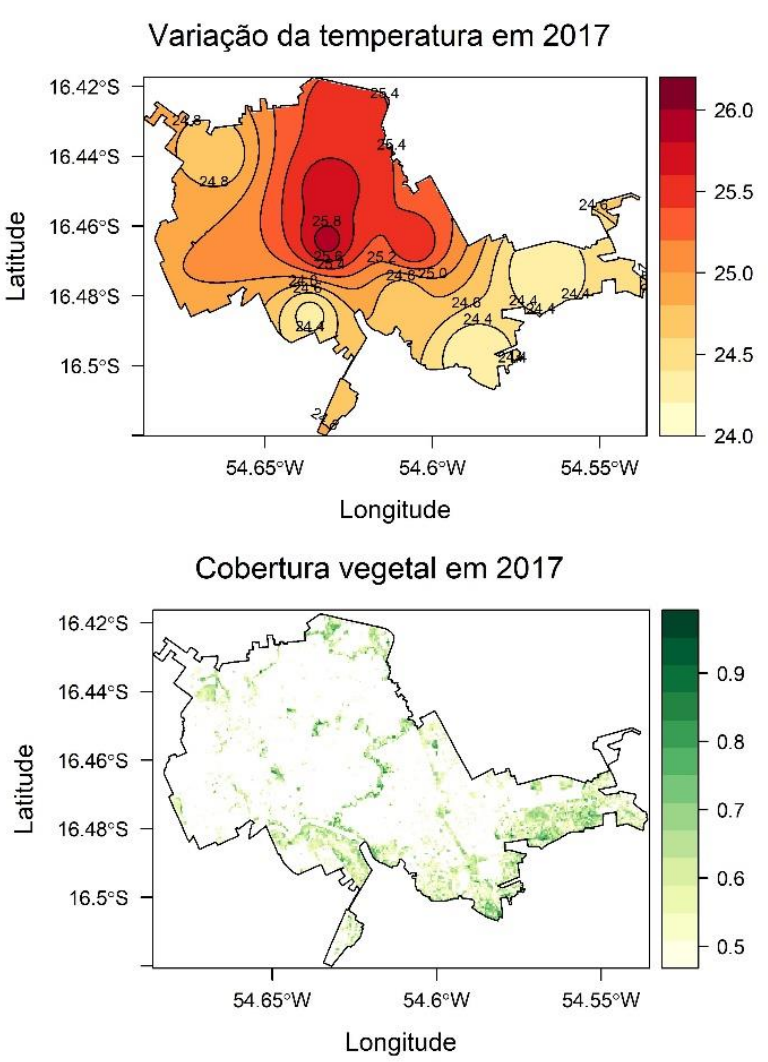

Figura 5. Variação da temperatura e da cobertura vegetal referente ao ano de 2013 e de 2017 para a área de estudo.

Pezzuto et al. (2015) realizaram um estudo dos efeitos da vegetação na variação da temperatura urbana na cidade de Campinas e Mendonza, na Argentina, simulando dados de vegetação no software ENVI-met. Constataram que a vegetação atua no resfriamento urbano, e que geralmente apresenta maior impacto na diminuição da temperatura máxima. Neste caso houve diminuição de $4,0{ }^{\circ} \mathrm{C}$ em Campinas e de $2,0{ }^{\circ} \mathrm{C}$ em Mendonza quando havia o incremento de $20 \%$ a
$60 \%$ de vegetação. Almeida et al. (2015), em um estudo da relação entre o índice de vegetação e a temperatura da superfície na cidade de Maceió-AL, observaram que havia uma tendência da temperatura diminuir quando próximo de valores NDVI a partir de 0.39 . O mesmo foi verificado neste estudo, onde há valores próximos de 0.70 , existe dossel mais denso, e temperaturas com médias mais baixas. Entretanto, observa-se que as menores médias de temperatura não dependem somente de altos valores de NDVI, mas também da 
quantidade da área coberta por vegetação (Figura 5).

Estes mesmos autores destacam que a maior presença de vegetação favorece a diminuição da temperatura do ar e da superfície em decorrência da baixa incidência de radiação solar que chega a superfície.

Leal et al. (2014) observam que quando há menor densidade de construção, maior quantidade de áreas permeáveis, concentração de remanescentes florestais ou espaços verdes públicos as temperaturas máximas tendem a diminuir. Isso enfatiza a importância de ações municipais para manter e implantar diferentes tipologias de florestas urbanas em áreas públicas e particulares da cidade para exercerem o papel no controle térmico urbano e também na drenagem das águas pluviais.

Em termos de coeficiente de correlação de Pearson para os valores extraídos do conjunto raster que constitui o mapa de cobertura vegetal de 2013 e de 2017, estão representados na Figura 6. A função linear obtida para esse caso possui um coeficiente de correlação (r) de 0,56 , isto é, houve uma moderada correlação entre as variáveis de estudo. Segundo Cunha et al. (2013), valores de coeficiente de correlação de Pearson (r) que estiverem entre 0.3 a 0.5 , é classificado como uma moderada correlação. Neste sentido, por se tratar de correlação moderada, não se atribui similaridades entre o conjunto de valores de NDVI para os anos estudados, corroborando com as diferenças de valores de área no levantamento da cobertura vegetal para cada ano em questão.

No teste $\mathrm{t}$ pareado (nível de $5 \%$ de significância), aceitou-se a hipótese de que há diferença significativa entre as duas amostras estudadas a um intervalo de confiança de $95 \%$. O p-valor foi de 0.03914. Com isto, houve diferenças no que tange à cobertura vegetal entre os anos estudados. Estes resultados estão em consonância com o teste de correlação de Pearson, demonstrando que as informações de cobertura vegetal são dispares, ou seja, a quantidade de cobertura vegetal para cada ano não é semelhante, mas que houve diferenças, neste caso o déficit, no ano de 2017 quando comparado com o ano de 2013.

Nota-se que nestes últimos cinco anos, principalmente no ano de 2018 , verificou-se que houve um déficit de cobertura vegetal na cidade de Rondonópolis comparado com anos anteriores, e isso pode estar atrelado à expansão urbana e ao crescente e desordenado mercado imobiliário. A abertura de novas áreas para habitação, onde frequentemente não há proteção efetiva de áreas protegidas pela legislação ambiental, exerce um

Pessi, D. P.; Rezende, G. B. M.; Silva, N. M. efeito negativo na qualidade ambiental urbana. Mais ainda, exerce efeitos sobre a temperatura e microclima urbano, como verificado neste estudo, onde houve aumento de até $1.5^{\circ} \mathrm{C}$, principalmente nas áreas com maior quantidade de área construída e pouca vegetação.

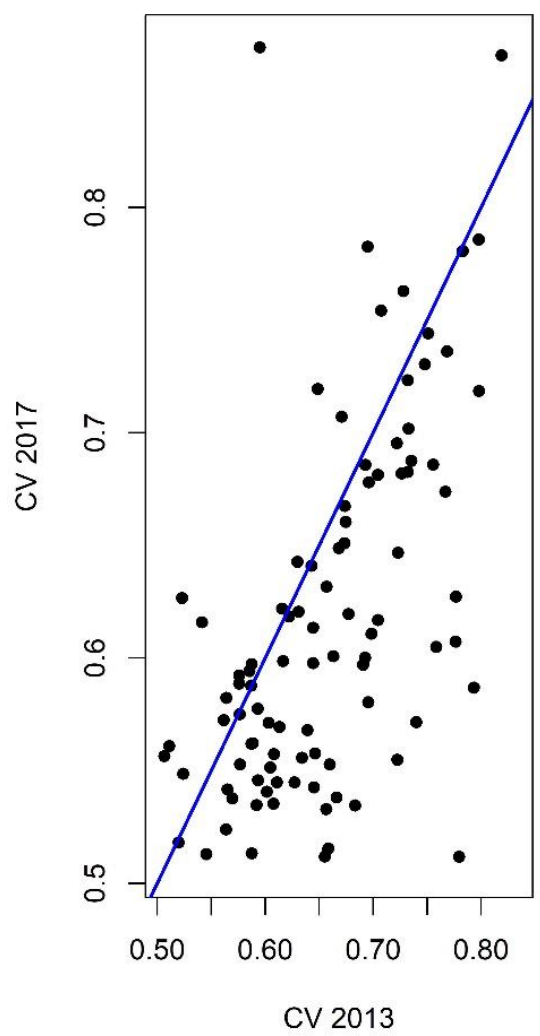

Figura 6. Correlação de Pearson entre os valores de cobertura vegetal do ano de 2013 e de 2017.

Com um bom planejamento ambiental urbano, áreas antes preservadas, poderiam se tornar unidades de preservação, parques, ou praças para recreação visto que para as proporções de Rondonópolis, há carência de áreas para lazer e parques florestados. O poder público, neste caso a prefeitura de Rondonópolis, deve revisar o PDM (Plano Diretor Municipal), para garantir ação efetiva na melhoria da condição de vida urbana, através da legislação ambiental, na tentativa de preservar áreas de papel social e biológico importantes.

\section{Conclusões}

A cobertura vegetal exerce importante papel nos centros urbanos. A vegetação urbana possui função de controle no microclima, diminuindo a temperatura do ar nos locais ou regiões que possuem maior quantidade de cobertura vegetal. Além disso, atua na hidrodinâmica das cidades, colaborando com a redução de inundações devido ao seu caráter de 
permeabilidade natural das águas pluviais. É importante destacar também, que as condições atmosféricas e a configuração do espaço urbano, proporcionam a ocorrência de uma maior concentração de material particulado inalável e que a cobertura vegetal urbana contribui de maneira decisiva (Cardoso et al., 2017) em diminuir a concentração de materiais particulados que são prejudiciais à saúde humana.

Outro ponto chave que a arborização exerce sobre o meio, é o reflexo sobre a saúde mental e bem-estar da população urbana, qualidade ambiental, estética e ambientes de recreação. Diante do exposto, torna-se importante e necessário que haja um prévio planejamento urbano-ambiental que considere a arborização da cidade no intuito de minimizar problemas atuais e evitar problemas futuros, tanto ambiental quanto à vida da população urbana, visto que no Brasil a maioria das pessoas vivem nas cidades. É importante que seja levado em conta o planejamento ambiental no Plano Diretor Municipal, visto que no Art. 42 do Estatuto das Cidades de Lei $\mathrm{n}^{\circ}$ 10.257/2001, ressalta a importância da presença efetiva de diretrizes para a preservação e ocupação das áreas verdes municipais.

\section{Referências}

Almeida, A.J.P., Guimarães Junior, S.A.M., Andrade, E.L., Neto, J.V.F., 2015. Relação entre o índice de vegetação e a temperatura da superfície na estimada e identificação das ilhas de calor na cidade de Maceió-AL. In: Simpósio Brasileiro de Sensoriamento Remoto, 17., João Pessoa. Anais. João Pessoa: Instituto Nacional de Pesquisas Espaciais, 2047-2054.

Angeoletto, F.H.S., 2008. Pelos quintais de Sarandi: ecologia urbana e planejamento ambiental. Maringá: Eduem 120.

Arruda, L.E.V., Silveira, P.R.S., Vale, H.S.M., Silva, P.C.M., 2013. Índice de área verde e de cobertura vegetal no perímetro urbano central do município de Mossoró-RN. Revista Verde de Agroecologia e Desenvolvimento Sustentável 8, 13-17.

Bargos, D.C., Matias, L.F., 2012. Mapeamento e análise de áreas verdes urbanas em Paulínia (SP): estudo com a aplicação de geotecnologias. Sociedade \& Natureza 24, 143-156.

Cardoso, K.M., Paula, A., Santos, J.S., Santos, M.L.P., 2017. Uso de espécies da arborização urbana no biomonitoramento de poluição ambiental. Ciência Florestal 27, 535-547.

Cunha, P.C.R., Nascimento, J.L., Silveira, P.M., Alves Júnior, J., 2013. Eficiência de métodos

Pessi, D. P.; Rezende, G. B. M.; Silva, N. M. para o cálculo de coeficientes do tanque classe A na estimative da evapotranspiração de referência. Pesq. Agropec. Trop. 43, 114-122.

Canholi, A.P., 2005. Drenagem urbana e controle de enchentes. São Paulo: Oficina de Textos, 302.

Demamann, M.T.M., 2011. Rondonópolis - MT: campo, cidade e centralidades. Tese (Doutorado em Geografia) - USP, São Paulo, 248.

Dunnington, D., 2017. prettymapr: Scale Bar, North Arrow, and Pretty Margins in R. R package version 0.2.2. https://CRAN.Rproject.org/package=prettymapr

Duarte, T.E.P., Angeoletto, F.H.S., Santos, J.W.M.C., Leandro, D.S., Bohrer, J.F.C., Vacchilano, M.C., Leite, L.B., 2017. O papel da cobertura vegetal nos ambientes urbanos e sua influência na qualidade de vida nas cidades. Editora Unijui 15, 175-203.

Gelaro, R., Mccarty, W., Suárez, M.J., et al., 2017. The modern-Era retrospective analysis for research and applications, version 2 (MERRA2). American Meteorological Society 30, 54195454.

Gamarra, N.L.R., Corrêa, M.P., Targino, A.C.L., 2014. Utilização de sensoriamento remoto em análises de albedo e temperatura de superfície em Londrina-PR: contribuições para estudos de ilhas de calor urbana. Revista Brasileira de Meteorologia 29, 537-550.

Hijmans, R.J., 2017. raster: Geographic Data Analysis and Modeling. R package versio 2.6-7. https://CRAN.R-project.org/package=raster

Harder, I.C.F., 2002. Inventário quali-quantitativo da arborização e infra-estrutura das praças da cidade de Vinhedo (SP). Dissertação (Mestrado em Agronomia) - Escola Superior de Agricultura Luiz de Queiroz, Piracicaba, 122.

IBGE. Instituto Brasileiro de Geografia e Estatística, 2017. Cidades@. Mato Grosso, Rondonópolis. Disponível em: < https://cidades.ibge.gov.br/brasil/mt/rondonopo lis/panorama >. Acesso em 31 de maio de 2017.

Kaand, D., Wickham, H., 2013. ggmap: Spatial Visualization with ggplot2. The R Journal, 5(1), 144-161. URL http://journal.rproject.org/archive/2013-1/kahle-wickham.pdf

Landsat-8, 2013, 20/04/2013. NASA EOSDIS Land Processes DAAC, USGS Earth Resources Observation and Science (EROS) Center, Sioux Falls, South Dakota (https://lpdaac.usgs.gov), acesso em: 13/05/2018.

Landsat-8, 2013, 04/05/2018. NASA EOSDIS Land Processes DAAC, USGS Earth Resources Observation and Science (EROS) Center, Sioux Falls, South Dakota (https://lpdaac.usgs.gov), acessado em: 13/05/2018. 
Lamigueiro, P.O., Hijmans, R., 2018. rasterVis. R package version 0.45 .

Leal, L., Biondi, D., Batista, A.C., 2014. Efeitos da vegetação na variação térmica da cidade de Curitiba, PR. FLORESTA 44, 451-464.

Zambrano-Bigiarini, M., 2017. hydroTSM: Time Series Management, Analysis and Interpolation for Hydrological ModellingR package version 0.5-1.

URL

NASA. National Aeronautics and Space Administration. Giovanni [online]. Disponível em: < https://giovanni.gsfc.nasa.gov/giovanni/ $>$. Acessado em: 17/04/2018.

Negri, S.M., 2008. O processo de segregação sócio espacial no contexto do desenvolvimento econômico da cidade de Rondonópolis - MT. 2008. Tese (Doutorado em Geografia) - Unesp, Rio Claro 180.

Nucci, J.C., Cavalheiro, F., 1999. Cobertura vegetal em áreas urbanas - conceito e método. Revista GEOUSP 6, 29-36.

Nucci, J.C., 2001. Qualidade ambiental e adensamento urbano: um estudo de Ecologia e Planejamento da Paisagem aplicado ao distrito de Santa Cecília (MSP). São Paulo: Humanitas - FFLCH/USP, 235.

Paula, I.F.M., Ferreira, C.C.M., 2017. Avaliação e mapeamento da cobertura vegetal da região central da cidade de Juiz de Fora-MG. Revista Ra'ega 39, 146-166.

Pinheiro, L.C.S.J., Castro, A.S., Martins, E.S., 2008. Levantamento das classes de solo existentes nas ecorregiões inseridas no limite do cerrado contínuo. In: IX Simpósio Nacional do Cerrado: Desafios e estratégias pra o equilíbrio entre sociedade, agronegócio e recursos naturais. II Simpósio Internacional Savanas Tropicais 10, 106-127.

Pezzuto, C.C., et al., 2015. Efeito da Vegetação na Variação da Temperatura Urbana em Diferentes Climas: estudo de caso na cidade de Campinas e Mendonza. In.: XIII Encontro Nacional e IX Encontro Latino-americano de Conforto no Ambiente Construído - ENCAC/ ENLACAC 2015, 1-10.QGIS Development Team 2018. QGIS Geographic Information System. Open Source Geospatial Foundation Project. http://qgis.osgeo.org.

Rezende, G.B.M., 2015. As cidades e as águas: uma abordagem metodológica das vulnerabilidades socioambientais dos rios Araguaia e das Graças, nos municípios de Barra do Garças, Pontal do Araguaia e Aragarças. Tese (Doutorado em Recursos Naturais) Universidade Federal de Campina Grande, Centro de Tecnologia e Recursos Naturais. Rondonópolis, 268.

Pessi, D. P.; Rezende, G. B. M.; Silva, N. M.
https://github.com/hzambran/hydroTSM.

DOI:10.5281/zenodo.839864.

Zambrano-Bigiarini, M., 2017. hydroGOF: Goodness-of-fit functions for comparison of simulated and observed hydrological time series $\mathrm{R}$ package version 0.3-10. URL http://hzambran.github.io/hydroGOF/. DOI:10.5281/zenodo. 8400

Rezende, G.B.M., Araújo, S.M.S., 2016. O planejamento dos aspectos da água no ambiente urbano. In: ARAÚJO, S. M. S. (Org.). Rios e homens: cursos transformados na relação sociedade-natureza. Paulo Afonso: SABEH, 3353.

Rouse, J.W., Haas, R.H., Schell, J.A., Deering, D.W., 1973. Monitoring vegetation systems in the Great Plains with ERTS, Third ERTS Symposium, NASA SP 351, 309-317.

$\mathrm{R}$ Core Team (2018). R: A language and environment for statistical computing. $R$ Foundation for Statistical Computing, Vienna, Austria. URL https://www.R-project.org/.

Roger Bivand and Nicholas Lewin-Koh (2017). maptools: Tools for Reading and Handling Spatial Objects. R package version 0.9-2. https://CRAN.R-project.org/package=maptools

Sarkar, D., 2008. Lattice: Multivariate Data Visualization with R. Springer, New York.ISBN 978-0-387-75968-5

Sarkar, D., Andrews, F., 2016. latticeExtra: Extra Graphical Utilities Based onLattice. $R$ package version 0.6-28. https://CRAN.Rproject.org/package=latticeExtra

Sette, D.M., 2005. Os climas do cerrado do centrooeste. In: Revista Brasileira de Climatologia 1, 29-42.

Sentinel-2, 2015, 14/05/2018. NASA EOSDIS Land Processes DAAC, USGS Earth Resources Observation and Science (EROS) Center, Sioux Falls, South Dakota (https://lpdaac.usgs.gov), acessado 14/05/2018.

Souza, A.P., Mota, L.L., Zamadei, T., Martim, C.C., Almeida, F.T., Paulino, J., 2013. Classificação climática e balanço hídrico climatológico no Estado de Mato Grosso. Nativa 1, 34-43.

Souza, M.R., Scopel, I., Martins, A.P., 2014. Áreas verdes no sítio urbano de Jataí-GO. Caminhos de Geografia 15, 181-198.

Tian, Y., Jim, C.Y., Tao, Y., Shi, T., 2011. Landscape ecological assessment of green space fragmentation in Hong Kong. Urban Forestry \& Urban Greening, Elsevier GmbH 10, 79-86.

Tucci, C.E.M., 1997. Plano diretor de drenagem urbana: princípios e concepção. RBRH Revista Brasileira de Recursos Hídricos 2, 5-12. 